\title{
Technique smart control soil moisture system to watering plant based on IoT with arduino uno
}

\author{
Mohanad Ali Meteab Al-Obaidi ${ }^{1}$, Muna Abdul Hussain Radhi ${ }^{2}$, Rasha Shaker Ibrahim ${ }^{3}$, Tole Sutikno ${ }^{4}$ \\ ${ }_{1,2,3}$ Department of Computer Science, College of Science, Mustansiriya University, Baghdad, Iraq \\ ${ }^{4}$ Department of Electrical Engineering, Universitas Ahmad Dahlan, Yogyakarta, Indonesia \\ ${ }^{4}$ Embedded System and Power Electronics Research Group (ESPERG), Yogyakarta, Indonesia
}

\begin{tabular}{l} 
Article Info \\
\hline Article history: \\
Received Nov 11, 2019 \\
Revised Feb 6, 2020 \\
Accepted Apr 23, 2020 \\
\hline
\end{tabular}

\section{Keywords:}

Arduino uno R3

Drip irrigation

FC-28 soil hygrometer

Volumetric sensors

Soil moisture sensors

\begin{abstract}
Water scarcity has become the most important challenge facing the world and a source of fear to the global community from the spread of famines due to the lack of agricultural production. For this reason, researchers seek to optimize the use of food resources, including water wealth. This project contributes to the legalization of the use of water resources. One of these methods is to solve the problem of a decrease in water resources, is drip irrigation systems. An affordable system was developed using soil moisture FC-28 hygrometer sensor compatible with arduino uno R3 and sending electrical signals based on voltage difference due to increased or decreased water in the soil to the monitor through the arduino for decision to operate irrigation pumps. The system is controlled by a software that allows the user to know the current state of the soil to choose the type of plant to determine the amount of water and the possibility of adding new types of plants to the program library and other features.
\end{abstract}

This is an open access article under the CC BY-SA license.

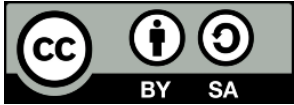

Corresponding Author:

Mohanad Ali Meteab Al-Obaidi,

Dept. of Computer Science, College of Science,

Mustansiriya University, Baghdad, Iraq.

Email: Neros2210@uomustansiriyah.edu.iq

\section{INTRODUCTION}

The growth of crops depends on the availability of land and arable water and an increase in investment in modern agricultural methods. Main challenges [1-6] that hamper agricultural development around the world due to the scarcity of water resources $[7,8]$ due to major climate changes and offset by an increase in the world's population and weak water consumption, which leads to increased demand for food. Therefore, it requires research on water resources, recycling, appropriate use of water and improvement of irrigation systems, including drip irrigation systems [9-11]. A drip irrigation system is an effective way to provide water for both plants and seasonal field crops [12, 13]. Drip irrigation provides an opportunity to flow water continuously and regularly [14-18], it also provides an opportunity for continuous flow of water in addition to many advantages in reducing water consumption and ensuring equitable agricultural distribution between plants, in light of humidity [19-21], temperature, agricultural soils and fertilizers used [22, 23], also reduces traditional losses such as deep filtration, runoff and increased soil salinity [24-28].

The drip irrigation system is a solution to many problems in dryland cultivation and improving the efficiency of agriculture through drip irrigation. The results showed that the majority of farmers appreciated the benefits such as saving water, reducing the cost of workers, increasing agricultural production and increasing its quality, simplifying the use of water, and limiting the spread of weeds [21, 29-32]. 
Swapnali and other researchers in 2018 used soil moisture sensors to sense the temperature and humidity, raspberry $\mathrm{Pi}$ with USB camera installed to surveillance the fields by internal network system [33]. The researchers G. P. and K., in 2016 have been able to measure soil moisture and temperature using moisture and temperature sensor. The drip irrigation valves open by a microcontroller. The irrigation status is updated using the PC. LCD using to display soil PH, temperature and humidity [34] .

Kumar [16] in 2017 used the automatic plant irrigation system with arduino uno R3 and soil sensor to the senses moisture level in the soil and sending a signal to the water pump for turn ON or OFF. Humidity sensors were placed in two different places to measure humidity, and then the signal was transmitted to the arduino to estimate the amount of water [35]. Some researchers in 2019 had built a system based on microcontroller and soil moisture sensors. They used platform mobile to display moisture percentage data in graphical form, if it was found that the percentage of soil moisture with an initial value of 30-35\% increased to $68.2 \%$, so the system has open the valves to watering the plants [4]. Arduino uno, two humidity sensors, submersible water pumps, and relay mechanism are used in this research.

\section{PROPOSED SYSTEM}

The main objective of this research is to design an automatic plant irrigation system to control the amount of water using arduino uno R3 and soil moisture sensors and control of the system continuously through the monitoring station and scheduling the irrigation system by selecting the type of plant from botanical library that was proposed and contribute to reducing all costs (water, labor) and increase the agricultural production. The majority of soil moisture sensors are used depending on the relationship between soil moisture and the electrical potential difference. Table 1 illustrated the famous of moisture soil sensor [16-18].

Table 1. Famous types of moisture soil sensors

\begin{tabular}{ll}
\hline \multicolumn{1}{c}{ Types } & \multicolumn{1}{c}{ Its items } \\
\hline 1-Volumetric sensors & 1-Refractometry (TDR) sensors, \\
& 2-Time Domain Transmissiometry (TDT) sensors, \\
& 3-Capacitance or Frequency Domain Refractometry (FDR) sensors \\
2-Tensiometers & To measure the tension between soil particles and water molecules. \\
3-Solid soil moisture sensor & 1-Gypsum blocks \\
& 2-Granular matrix sensors. \\
4-Single-Point Measurement & 1-ECH2O EC-52-CS650 \\
\hline
\end{tabular}

The proposed system is a sustainable solution to enhance the efficiency of using water in agricultural fields according to the requirements of plants. This system works by using drip irrigation by connecting the sensors of the irrigation system to arduino uno and can be monitoring the system's operation through a computer, and the ability to choose the types of plants according to the program of the system, depending to the soil's need for moisture in the plant root area. The automatic irrigation system for farmers allows to determining the necessary amounts of water in due course. The proposed system is distinguished from other systems by automating the irrigation system by computer.

\section{RESEARCH METHOD}

As far as this proposed system concerned, the use of the automation irrigation sensor is a purpose of improving water use efficiency, the irrigation sensors provide information to the control system on how much water the cultivated land needs and the amount of water spent and the provide the system user with instant reports about water pumps which are turn ON or OFF. The main used hardware components in this research are: arduino uno R3, FC-28 soil hygrometer, water pumps, transistor 2n222, resistor (220 Ohm), connecting wires, batteries $(5 \mathrm{~V})$, pipes and drip, network of valves water, and line drip tube.

\subsection{Soil moisture sensor}

Uses the moisture sensor in the soil is used by implanting two electrodes (cathode anode) in the agricultural soil and after the water flows into the soil, these electrodes are affected electrically and send signals representing the electric voltage difference to arduino device and then to the pc to close or open the valves to ensure flow or close the water. Figure 1 shows the electrical circuit work. The soil moisture sensor consists of three pins (VCC, GND, SIG), VCC is the regulated DC supply voltage, GND is the ground, and the third (SIG) to send the signal to one of arduino's serial ports for reading soil moisture. 


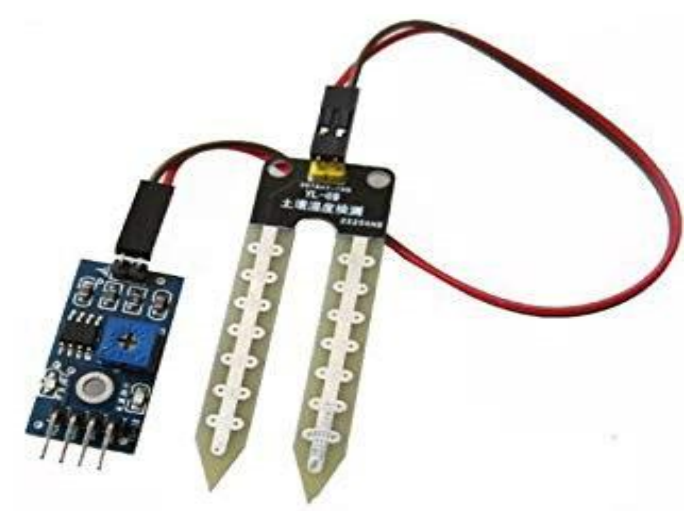

Figure 1. Soil moisture FC-28 soil hygrometer sensor

\subsection{Circuit arduino and soil moisture sensor}

Usually, water pumps need more electrical energy than the arduino board can provide, so pumps must be connected to an external power source. To control the opening or closing of the pump circuit, $2 \mathrm{n} 2222$ transistor is used in this work as switch in arduino circuit, to open and close the pump circuit by sending an electrical signal from one of its digital ports to transistor and the signal is either $(5 \mathrm{~V})$ or $(0 \mathrm{~V})$ to turn the pump ON or OFF. Figure 2 illustrated the circuit of arduino uno R3 with the soil moisture sensor.

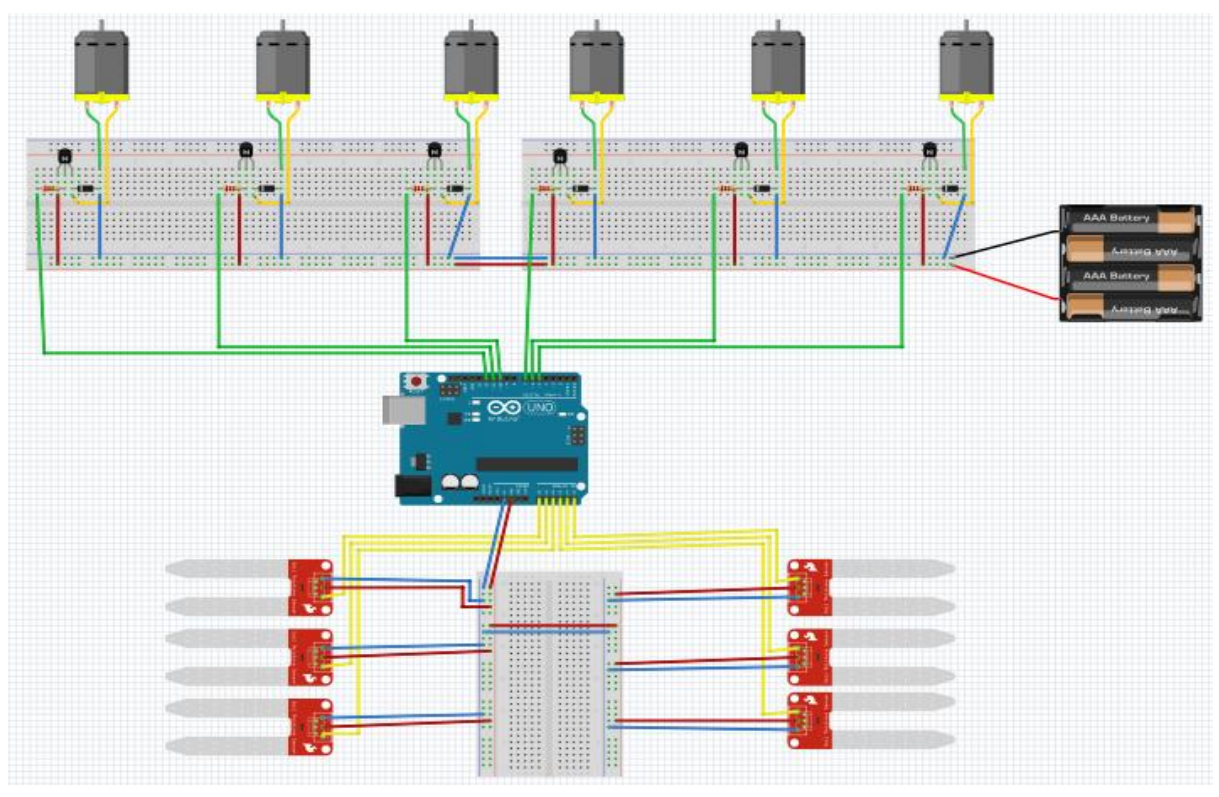

Figure 2. Circuit arduino and soil moisture sensor with water pump

\subsection{Software design}

The flowchart in Figure 3 shows the sequential steps for the system progress, from selecting the plant types to determine the quantity of water needed for each type of plant and then operating humidity sensors to determine whether the soil needs water and printing reports on the amount of water spent within 24 hours. Figure 3 shows the steps of how the system works.

\subsection{Operating system process stages}

Initially, when the program is started by PC, all soil moistures sensors remain in waiting state until the plant type is chosen from the plant library then choosing the plant fields to be irrigated depending on humidity sensors to turn ON water pump in the light of the quantity of moisture measured by the soil moisture sensors as shown in the Figure 4. 


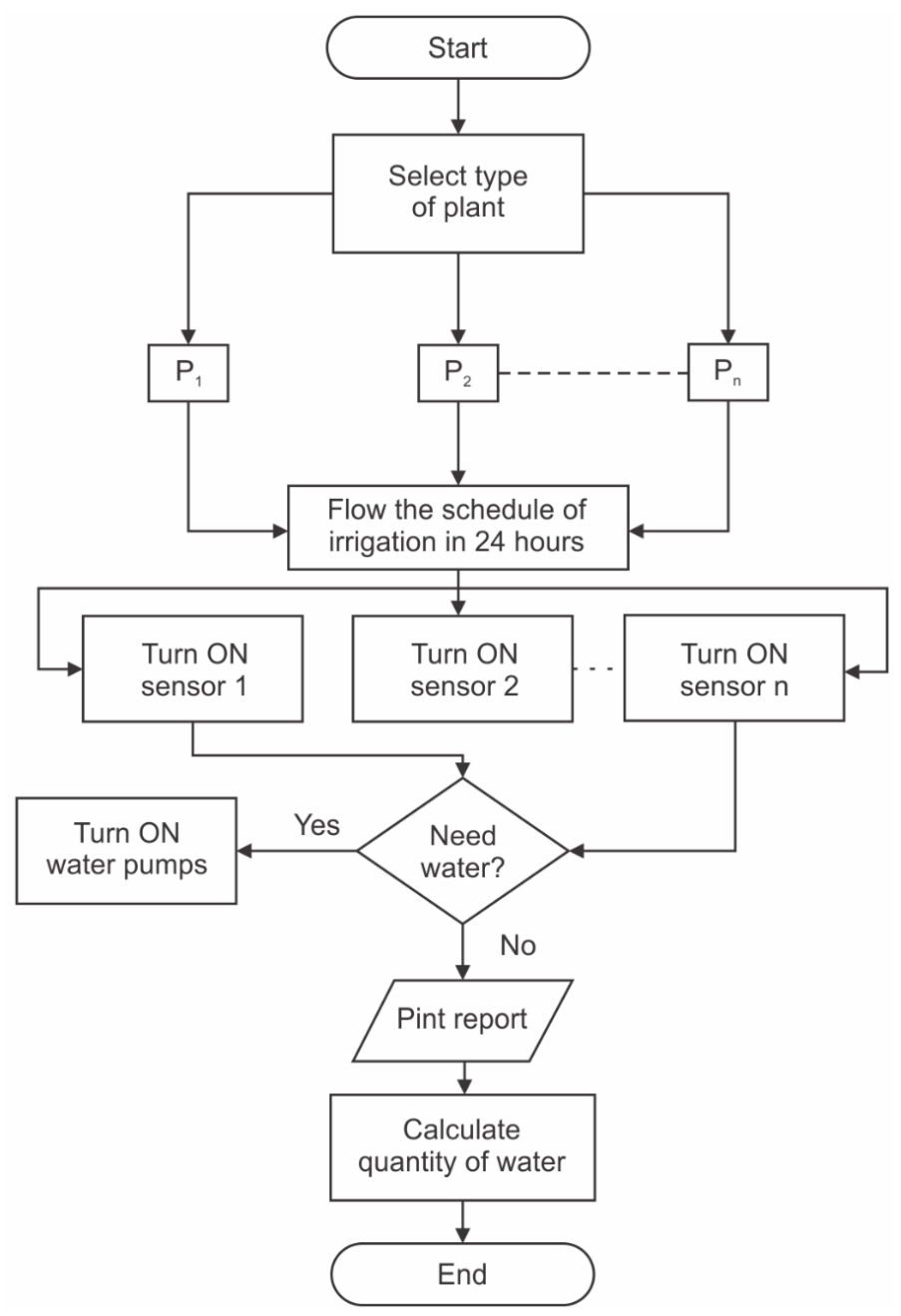

Figure 3. Flowchart of the system's work steps

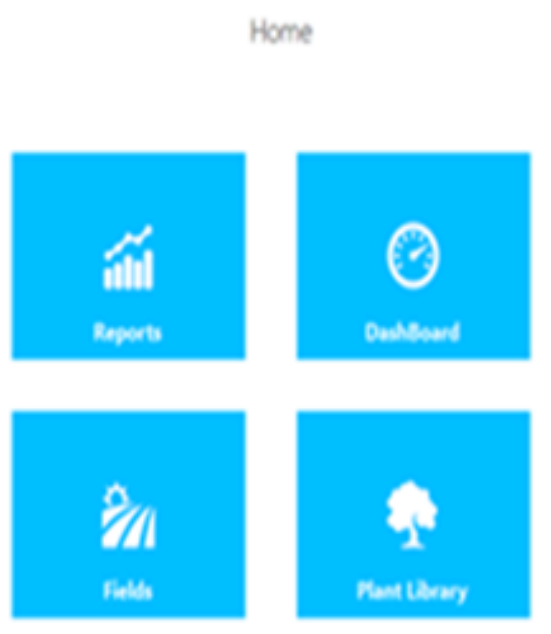

(a)

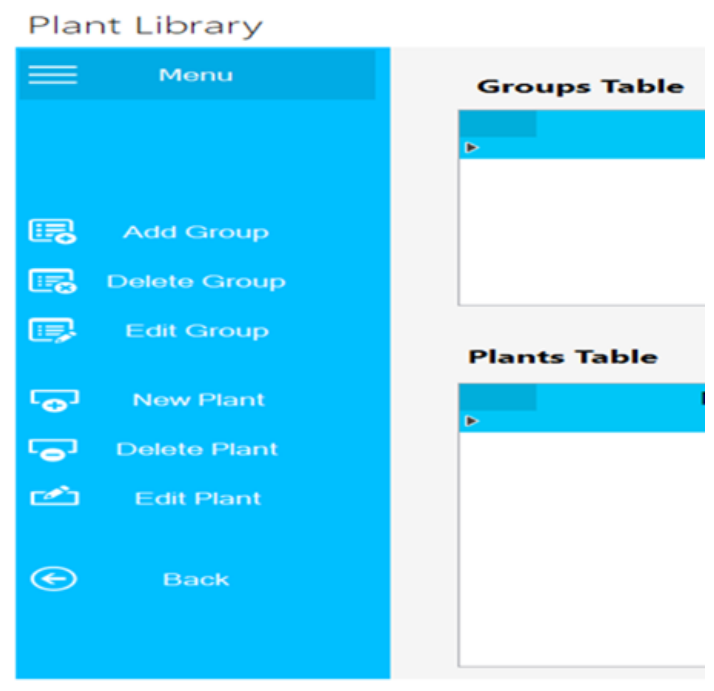

(b)

Figure 4. Main window of the proposed system, (a) Home, (b) Plant library 


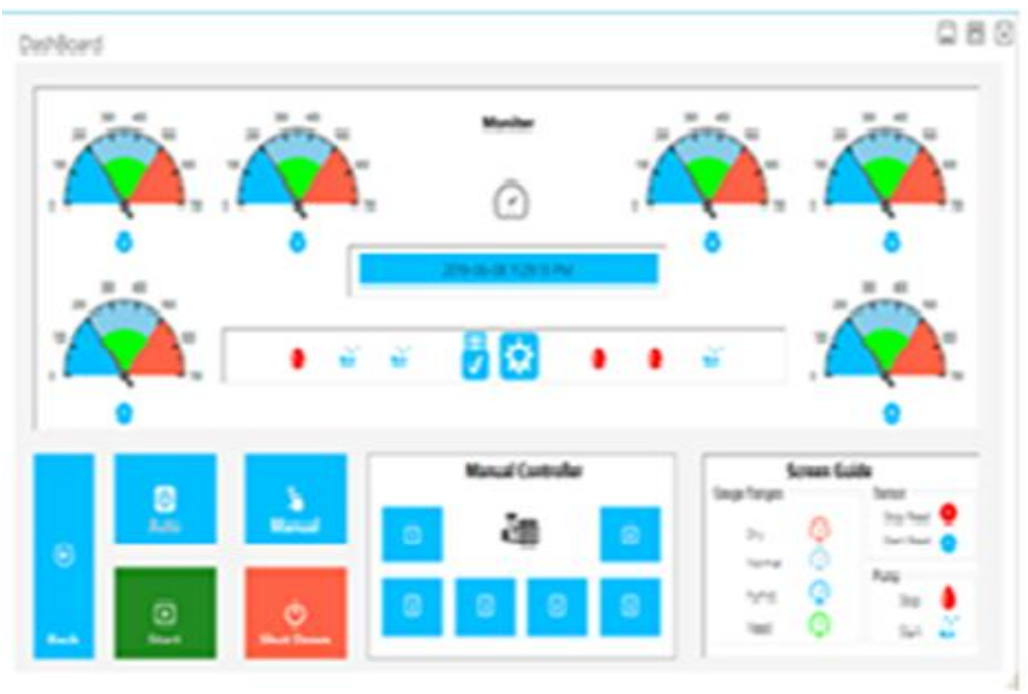

(c)

Figure 4. Main window of the proposed system, (c) Dashboard (Continue)

\section{RESULTS AND DISCUSSION}

A status report can be requested the situation of the quantity of water spent in each agriculture field as reflected in Figure 5 this allows continuous monitoring of sensors humidity in the plant field and water pumps which are working. Data can also be modified on the plant and new plant species are introduced. There is a large plant database with the amount of water suitable for each plant type as illustrated in Figure 6. An experiment was conducted on an agricultural field with an area of one thousand meters divided into four areas, it is about 250 meters per one, and a set of humidity sensors were distributed evenly in the soil to turn ON the irrigation drips systems, and the results were obtained as shown in the Figure 7.
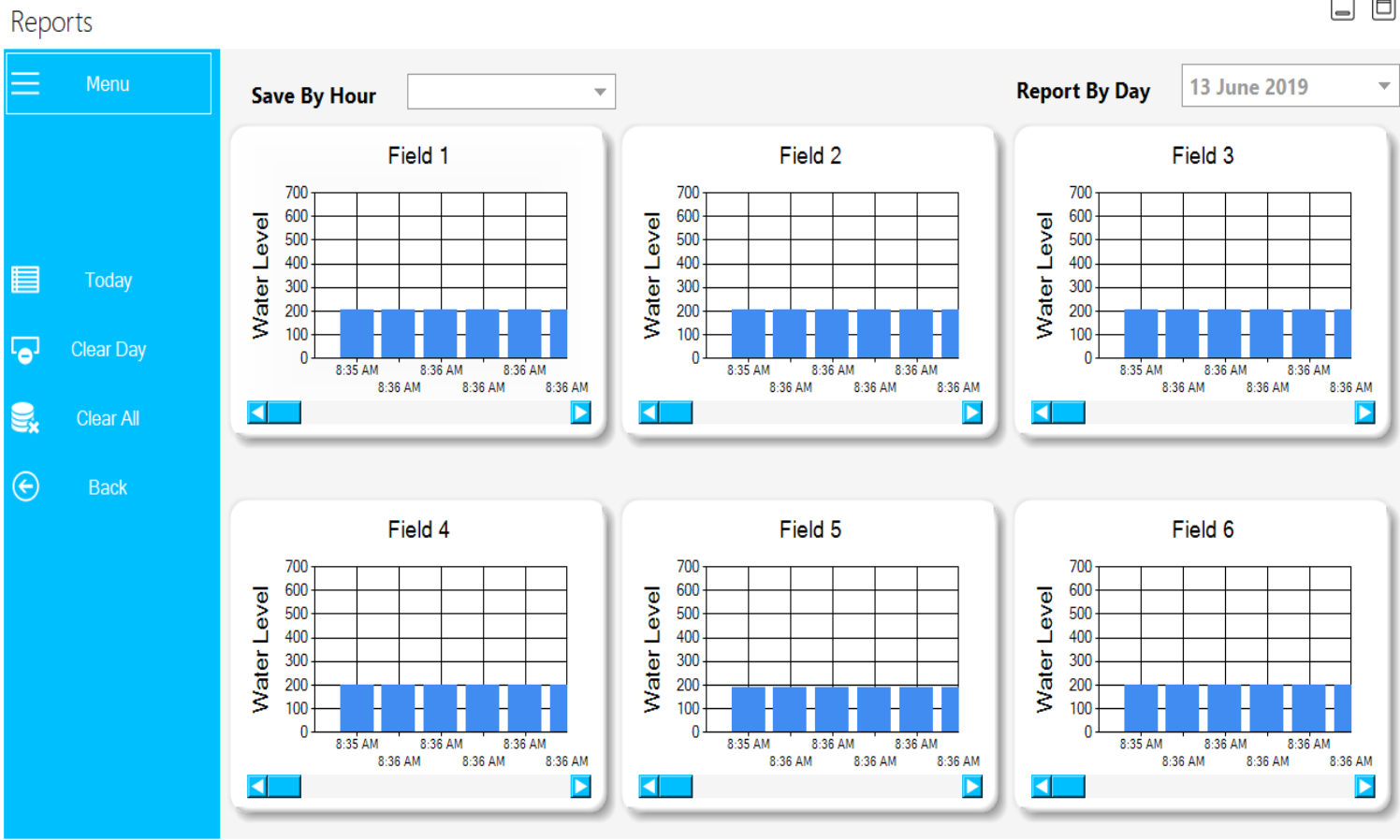

Figure 5. Report for situation quantity of water spent in each field 


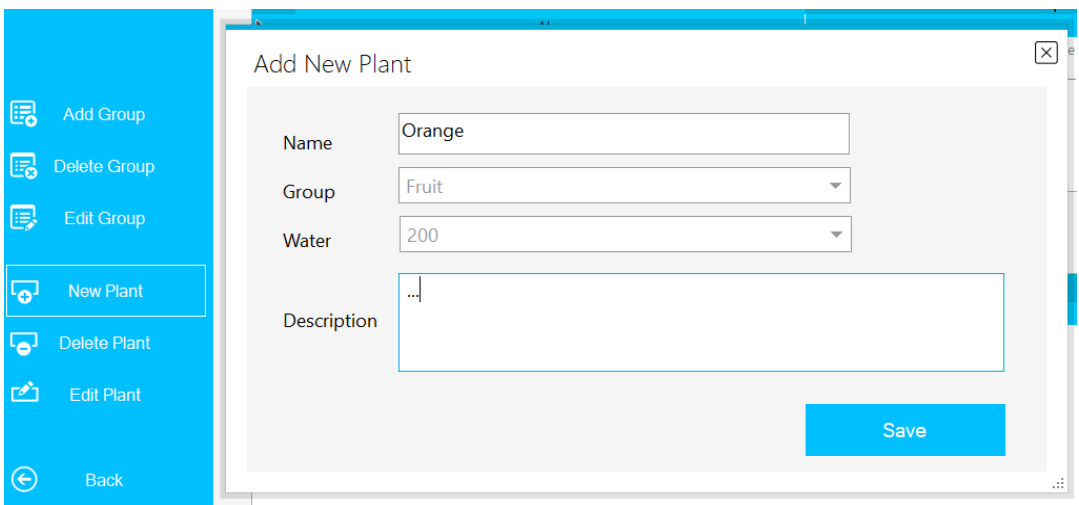

Figure 6. Edit plant library

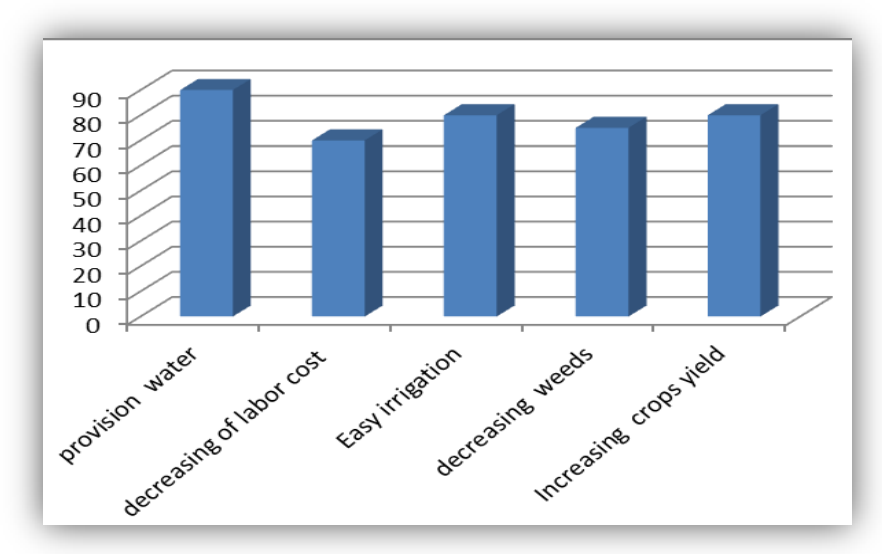

Figure 7. Benefits of drip irrigation

\section{CONCLUSION}

The drip irrigation system is one of the systems in Internet of Things (IoT) that depend on sensors and automatic control in system through a computer system that is connected to arduino uno R3. The proposed system aims to know the level of moisture in the soil and then water the land with the necessary water, depending on the type of plant and the amount of water allocated to it. This system reduced reliance on the human factor and reduced energy costs, in addition to increasing yields of crops and a decrease in the amount of wasted water. The system can be developed by adding other sensors such as temperature and the air humidity and using a GPS to monitor the status and control of all devices remotely by mobile.

\section{REFERENCES}

[1] N. Agrawal and S. Singhal, "Smart drip irrigation system using raspberry pi and arduino," International Conference on Computing, Communication \& Automation, Noida, pp. 928-932, 2015.

[2] D. Bansal and S. Reddy, "WSN based closed loop automatic irrigation system," International Journal of Engineering Science and Innovative Technology (IJESIT), vol. 2, no. 3, pp. 229-237, 2013.

[3] M. Roopaei, P. Rad and K. R. Choo, "Cloud of Things in Smart Agriculture: Intelligent Irrigation Monitoring by Thermal Imaging," in IEEE Cloud Computing, vol. 4, no. 1, pp. 10-15, Jan.-Feb. 2017.

[4] J. M. Waworundeng, N. C. Suseno, and R. R. Y. Manaha, "Automatic Watering System for Plants with IoT Monitoring and Notification," CogITo Smart Journal, vol. 4, no. 2, pp. 316-326, 2019.

[5] B. Will and I. Rolfes, "A miniaturized soil moisture sensor based on time domain transmissometry," 2014 IEEE Sensors Applications Symposium (SAS), Queenstown, pp. 233-236, 2014.

[6] C. Yoon, M. Huh, S. Kang, J. Park and C. Lee, "Implement smart farm with IoT technology," 2018 20th International Conference on Advanced Communication Technology (ICACT), pp. 749-752, 2018.

[7] H. Ben Ali, M. Hammami, A. Saidi, and R. Boukchina, "Assessment of a new approach for systematic subsurface drip irrigation management," International Journal of Agronomy, 2017. 
[8] S. Bhunia, I. Verma, M. Arif, R. Gochar, and N. Sharma, "Effect of crop geometry, drip irrigation and bio-regulator on growth, yield and water use efficiency of wheat (Triticum aestivum L.)," International Journal of Agricultural Sciences, vol. 11, no. 1, pp. 45-49, 2015.

[9] G. Bitella, R. Rossi, R. Bochicchio, M. Perniola, and M. Amato, "A novel low-cost open-hardware platform for monitoring soil water content and multiple soil-air-vegetation parameters," Sensors, vol. 14, no. 10, pp. 19639-19659, 2014.

[10] A. Bonfante, E. Monaco, P. Manna, R. De Mascellis, A. Basile, M. Buonanno, et al., "LCIS DSS-An irrigation supporting system for water use efficiency improvement in precision agriculture: A maize case study," Agricultural Systems, vol. 176, pp. 1-14, November 2019.

[11] O. A. Hammood, M. N. M. Kahar, W. A. Hammood, R. A. Hasan, M. A. Mohammed, A. A. Yoob, et al., "An effective transmit packet coding with trust-based relay nodes in VANETs," Bulletin of Electrical Engineering and Informatics, vol. 9, no. 2, pp. 685-697, 2020.

[12] L. Colizzi, D. Caivano, C. Ardito, G. Desolda, A. Castrignanò, M. Matera, et al., "Chapter 1-Introduction to agricultural IoT," in Agricultural Internet of Things and Decision Support for Precision Smart Farming, A. Castrignanò, G. Buttafuoco, R. Khosla, A. M. Mouazen, D. Moshou, and O. Naud, Eds., ed: Academic Press, pp. 1-33, 2020.

[13] A. D’Ausilio, "Arduino: A low-cost multipurpose lab equipment," Behavior research methods, vol. 44, pp. 305-313, 2012.

[14] F. R. de Miranda, "A site-specific irrigation control system," in 2003 ASAE Annual Meeting, American Society of Agricultural and Biological Engineers, Las Vegas, Nevada, USA, 2003.

[15] M. Dener, "WiSeN: A new sensor node for smart applications with wireless sensor networks," Computers \& Electrical Engineering, vol. 64, pp. 380-394, November 2017.

[16] A. Kumar and S. Magesh, "Automated Irrigation System Based on Soil Moisture Using Arduino," International Journal of Pure and Applied Mathematics, vol. 116, no. 21, pp. 319-323, 2017.

[17] M. Mahbub, "A smart farming concept based on smart embedded electronics, internet of things and wireless sensor network," Internet of Things, vol. 9, March 2020.

[18] D. Novianto, I. Setiyowati, and E. Purnomo, "Design and calibration soil moisture sensor for rise seedling using Arduino nano as a controller," in AIP Conference Proceedings, vol. 2097, no. 1, 2019.

[19] J. O. Payero, A. M. Nafchi, R. Davis, and A. Khalilian, "An Arduino-based wireless sensor network for soil moisture monitoring using Decagon EC-5 sensors," Open Journal of Soil Science, vol. 7, no. 10, pp. 288-300, 2017.

[20] G. M. Spinelli, Z. L. Gottesman, and J. Deenik, "A low-cost Arduino-based datalogger with cellular modem and FTP communication for irrigation water use monitoring to enable access to CropManage," HardwareX, vol. 6, 2019.

[21] N. Sudharshan, A. V. S. K. Karthik, J. S. S. Kiran, and S. Geetha, "Renewable Energy Based Smart Irrigation System," Procedia Computer Science, vol. 165, pp. 615-623, 2019.

[22] M. S. Farooq, S. Riaz, A. Abid, K. Abid and M. A. Naeem, "A Survey on the Role of IoT in Agriculture for the Implementation of Smart Farming," in IEEE Access, vol. 7, pp. 156237-156271, 2019.

[23] S. Ferdoush and X. Li, "Wireless Sensor Network System Design Using Raspberry Pi and Arduino for Environmental Monitoring Applications," Procedia Computer Science, vol. 34, pp. 103-110, 2014.

[24] S. A. Hamoodi, A. N. Hamoodi, and G. M. Haydar, "Automated irrigation system based on soil moisture using arduino board," Bulletin of Electrical Engineering and Informatics, vol. 9, no. 3, pp. 870-876, 2020.

[25] S. Hussain, N. Schofield and A. W. Matin, "Design of a Web-Based Application for Wireless Sensor Networks," International Workshop on Database and Expert Systems Applications (DEXA'06), pp. 319-326, 2006.

[26] O. A. Hammood, N. Nizam, M. Nafaa, and W. A. Hammood, "RESP: Relay Suitability-based Routing Protocol for Video Streaming in Vehicular Ad Hoc Networks," International Journal of Computers, Communications \& Control, vol. 14, no. 1, pp. 21-38, February 2019.

[27] M. A. Mohammed et al., "A Focal load balancer based algorithm for task assignment in cloud environment," International Conference on Electronics, Computers and Artificial Intelligence (ECAI), Iasi, Romania, pp. 1-4, 2018.

[28] Royida A. Ibrahem Alhayali, Munef Abdullah Ahmed, Yasmin Makki Mohialden, Ahmed H. Ali, "Efficient method for breast cancer classification based on ensemble hoffeding tree and naïve Bayes," Indonesian Journal of Electrical Engineering and Computer Science, vol. 18, no. 2, pp. 1074-1080, May 2020.

[29] M. A. Mohammed, I. A. Mohammed, R. A. Hasan, N. Țăpuş, A. H. Ali, and O. A. Hammood, "Green Energy Sources: Issues and Challenges," RoEduNet Conference: Networking in Education and Research (RoEduNet), pp. 1-8, 2019.

[30] M. A. Mohammed and N. ȚĂPUŞ, "A Novel Approach of Reducing Energy Consumption by Utilizing Enthalpy in Mobile Cloud Computing," Studies in Informatics and Control, vol. 26, no. 4, pp. 425-434, December 2017.

[31] N. Q. Mohammed, M. S. Ahmed, M. A. Mohammed, O. A. Hammood, H. A. N. Alshara and A. A. Kamil, "Comparative Analysis between Solar and Wind Turbine Energy Sources in IoT Based on Economical and Efficiency Considerations," International Conference on Control Systems and Computer Science, Romania, 2019.

[32] Z. H. Salih, G. T. Hasan, M. A. Mohammed, M. A. S. Klib, A. H. Ali and R. A. Ibrahim, "Study the Effect of Integrating the Solar Energy Source on Stability of Electrical Distribution System," 2019 22nd International Conference on Control Systems and Computer Science (CSCS), Bucharest, Romania, pp. 443-447, 2019.

[33] S. Pawar, P. Rajput, and A. Shaikh, "Smart irrigation system using IOT and raspberry pi," International Research Journal of Engineering and Technology, vol. 5, no. 8, pp. 1163-1166, 2018.

[34] G. Parameswaran and K. Sivaprasath, "Arduino based smart drip irrigation system using Internet of Things," Int. J. Eng. Sci, vol. 6, no. 5, pp. 5518-5521, 2016.

[35] P. Naik, A. Kumbi, C. N. Vishwanath Hiregoudar, S. B. Pavitra HK, and P. K. Sushmita JH, "Arduino Based Automatic Irrigation System Using IoT," International Journal of Scientific Research in Computer Science, Engineering and Information Technology, vol. 2, no. 3, pp. 1-5, 2017. 